\title{
Rapid diagnosis of cytomegalovirus encephalitis in patients with AIDS using in situ hybridisation
}

\author{
M Musiani, M Zerbini, S Venturoli, G Gentilomi, V Borghi, P Pietrosemoli, M Pecorari, \\ M La Placa
}

\begin{abstract}
Aims-To evaluate the presence of cytomegalovirus (CMV) DNA in the cerebrospinal fluid of patients with AIDS and suspected viral encephalitis using an in situ hybridisation assay with digoxigenin labelled CMV DNA probes.
\end{abstract}

Methods-The presence of CMV DNA was evaluated in cerebrospinal fluid cells of 10 patients with AIDS using in situ hybridisation. The positivity of CMV DNA was confirmed by the presence of CMV induced antigens in the same specimens. The presence of CMV DNA and CMV induced antigens was also analysed in peripheral blood leucocytes. The time required to perform the in situ hybridisation assay was about eight hours.

Results-The in situ hybridisation assay was sensitive, specific, and provided good resolution. Six patients proved positive for the presence of CMV DNA in CSF cells and all six also proved positive for CMV DNA in blood leucocytes. Of the six CMV positive patients, five were treated with specific antiviral drugs: of these, one died during the treatment while four clinically recovered after one month of treatment.

Conclusions-The in situ hybridisation assay using digoxigenin labelled CMV DNA probes can be used as a valuable diagnostic test for the detection of CMV DNA in the cerebrospinal fluid cells of patients with suspected CMV encephalitis and can therefore prompt adequate antiviral therapeutic intervention.

(F Clin Pathol 1994;47:886-891)

Institute of

Microbiology,

University of Bologna,

Italy

M Musiani

M Zerbini

$S$ Venturoli

G Gentilomi

M La Placa

Institute of Infectious Diseases, University of Modena, Italy

V Borghi

P Pietrosemoli

M Pecorari

Correspondence to: Dr Monica Musiani, Institute of Microbiology, Via Massarenti 9, 40138 Bologna, Italy

Accepted for publication 28 February 1994
In immunocompromised patients cytomegalovirus (CMV) can produce a variety of clinical syndromes, including chorioretinitis, oesophagitis, colitis, pneumonia, adrenalitis, and encephalitis. ${ }^{12} \mathrm{CMV}$ encephalitis is rare in immunocompromised transplant recipients while in patients with AIDS it seems to occur more frequently; in fact it has been described in up to $30 \%$ of such patients in post mortem histopathologic studies. ${ }^{34}$

CMV encephalitis represents a challenging problem. It has no uniform clinical presentation; radiological findings and brain computed tomography are not very specific and sensitive. ${ }^{5}$ Laboratory diagnosis generally relies on viral cultures of cerebrospinal fluid or demonstration of intrathecal production of specific immunoglobulins. However, during the early phase of the disease and in immunocompromised patients, these laboratory tests are often negative, leaving the definite diagnosis to the necropsy pathologist. ${ }^{6-8}$

Hybridisation techniques for CMV DNA have been suggested as a promising tool for the specific and reliable diagnosis of CMV infection. We recently reported the rapid and sensitive detection of CMV DNA in urine samples using dot blot hybridisation assays ${ }^{910}$ and the in situ detection of CMV DNA both in infected cultured cells and in biopsy specimens of patients with AIDS and concomitant CMV infection. ${ }^{11}{ }^{12}$ In those studies we used digoxigenin labelled CMV DNA probes, constructed in our laboratory. These proved highly specific and sensitive.

Early and rapid diagnosis of CMV encephalitis is essential for antiviral treatment; moreover, CMV can infect most central nervous system cells. ${ }^{613}$ Our study, therefore, evaluated the use of digoxigenin labelled CMV DNA probes in hybridisation assays on cerebrospinal fluid cell preparations, for an early diagnosis of CMV encephalitis.

\section{Methods}

Ten patients with AIDS and suspected subacute viral encephalitis were enrolled in the study. Six were men and four women. Five were intravenous drug misusers, two were homosexual men, and three patients had contracted HIV infection by heterosexual intercourse. Their ages ranged from 26-59 years. Diagnosis of encephalitis was based on clinical findings such as headache, fever, altered consciousness, seizures; on focal neurological signs; on radiological and computed tomography examination of the brain to show parenchymal abnormalities or non-specific cortical atrophy; and on examination of the cerebrospinal fluid. Bacterial, including mycobacterial, and cryptococcal encephalitis were excluded by negative cultures and negative antigen detection; toxoplasma encephalitis was not suspected given the absence of typical cerebral lesions on computed tomography.

Paired cerebrospinal fluid and blood samples were taken from the patients enrolled in the study. Cerebrospinal fluid was obtained by lumbar puncture; only samples free of blood contamination were used for further investigation. Cells from $2-3 \mathrm{ml}$ cerebrospinal fluid were collected by centrifugation at 1000 rpm for 10 minutes at room temperature and 
resuspended in phosphate buffered saline (PBS) $(0 \cdot 15 \mathrm{M}, \mathrm{pH} 7 \cdot 4)$, then cytocentrifuged on glass slides pretreated as described before. ${ }^{11}$ About 500 cells were analysed on each slide.

Cells were fixed in $4 \%$ paraformaldehyde in PBS for 30 minutes. After fixation cells were washed three times in PBS for 10 minutes each and then dehydrated with ethanol washes (at $30,60,80,95$, and $100 \%$ ) for five minutes each. Cells were then air dried and stored at $4^{\circ} \mathrm{C}$. Cells could be stored for at least a month with no decrease in their interaction with the hybridisation probe.

To study the presence of CMV DNA in peripheral blood polymorphonuclear leucocytes (PMNLs), PMNLs from $5 \mathrm{ml}$ of peripheral blood treated with EDTA were separated by sedimentation on a $6 \%$ dextran solution, centrifuged, and resuspended in PBS. ${ }^{14}$ They were then cytocentrifuged on pretreated glass slides and fixed as described above for cerebrospinal fluid cells.

Samples of cerebrospinal fluid cells, taken from patients with AIDS and cryptococcal encephalitis ( $n=5)$, mycobacterial encephalitis $(n=1)$, and toxoplasma encephalitis ( $n=$ 3) were analysed for the presence of $\mathrm{CMV}$ DNA.

\section{DNA PROBE}

The probe was constructed using the Towne CMV Xba I D fragment (20 kilobases) belonging to the repeated regions of the CMV genome. ${ }^{15}$ The $\mathrm{D}$ fragment was cloned in plasmid pACYC 184 and amplified in Escherichia coli HB 101.16 Routine methods for the large scale preparation of plasmid were used. ${ }^{17}$ The $\mathrm{D}$ fragment was separated from the pACYC 184 vector by electrophoresis in a $0.6 \%$ low melting point agarose gel. The D fragment was then recovered from the gel $^{17}$ and processed for labelling.

Probe labelling was carried out by incorporation of digoxigenin labelled deoxyuridine triphosphate (Dig-dUTP) (Boehringer) using the method of random primed DNA labelling, as described before. ${ }^{1819}$

Our digoxigenin labelled CMV DNA probe visualised $0.1 \mathrm{pg}$ of homologous DNA after dot blot hybridisation, followed by immunoenzymatic reaction with colorimetric detection. The CMV DNA probe could be stored at $-20^{\circ} \mathrm{C}$ for at least four months with no decrease in its activity.

\section{IN SITU HYBRIDISATION}

\section{Pretreatment of cells}

Cells were hydrated briefly in PBS and then placed in $0.02 \mathrm{~N} \mathrm{HCl}$ for 10 minutes. After three washes with PBS cells were treated with $0.01 \%$ Triton X-100 in PBS for two minutes. After a further three washes with PBS the cells were treated with pronase (Sigma) (0.5 $\mathrm{mg} / \mathrm{ml}$ ) in $0.05 \mathrm{M}$ TRIS-HCl buffer, $\mathrm{pH} 7 \cdot 6$, containing $5 \mathrm{mM}$ EDTA for five minutes. After pronase treatment the cells were washed twice with PBS containing $2 \mathrm{mg} / \mathrm{ml}$ glycine. After these treatments cell monolayers were postfixed with $4 \%$ paraformaldehyde in PBS for five minutes and washed twice with PBS containing $2 \mathrm{mg} / \mathrm{ml}$ glycine. Cells were then dehydrated by ethanol washes $(30,60,80,95$, and $100 \%$ ).

\section{Hybridisation reaction}

Dehydrated cells were overlaid with $10 \mu \mathrm{l}$ of the hybridisation mixture. The hybridisation mixture consisted of $50 \%$ deionised formamide, $10 \%$ dextran sulphate, $250 \mu \mathrm{g} / \mathrm{ml}$ carrier calf thymus DNA, and $2 \mu \mathrm{g} / \mathrm{ml}$ digoxigenin labelled probe DNA in $2 \times$ SSC buffer. ( $0.3 \mathrm{M}$ sodium chloride, $0.03 \mathrm{M}$ sodium cit-

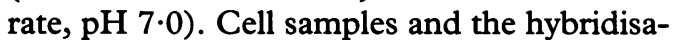
tion mixture containing the labelled probe were denatured together ${ }^{11}$ by heating in an $85^{\circ} \mathrm{C}$ water bath for six minutes, and were then left to hybridise at $37^{\circ} \mathrm{C}$ for three hours. After hybridisation cells were washed three times under stringent conditions. ${ }^{11}$

\section{Detection of hybridized probes}

Slides were briefly washed in a $150 \mathrm{mM}$ TRIS- $\mathrm{HCl}$ buffer ( $\mathrm{pH} 7 \cdot 5$ ) containing 150 $\mathrm{mM} \mathrm{NaCl}$. The blocking reagent (Boehringer) was applied to cell samples for $30 \mathrm{~min}$ utes at room temperature. After two washings for two minutes in TRIS- $\mathrm{HCl}$ buffer cells were incubated for 30 minutes with polyclonal anti-digoxigenin Fab fragments, conjugated to alkaline phosphatase (Boehringer), diluted 1 in 5000 in TRIS-HCl buffer. Unbound antibody was removed by two 15 minute washes with TRIS-HCl buffer. Cells were then equilibrated for two minutes with equilibration buffer (EB) (100 mM TRIS$\mathrm{HCl}, 100 \mathrm{mM} \mathrm{NaCl}, 50 \mathrm{mM} \mathrm{MgCl}_{2}, \mathrm{pH}$ $9 \cdot 5)$, and were then treated with alkaline phosphatase substrate, as described before. ${ }^{11}$ The development of a dark blue coloured precipitate at the enzyme site in positive cells was monitored by microscopic examination. The reaction was usually complete after about 15 minutes. Cells were washed for five minutes with TE buffer (100 mM TRIS- $\mathrm{HCl}, 1$ mM EDTA), pH 8, mounted with $50 \%$ glycerol in PBS, and examined by light microscopy.

For each experiment, positive and negative controls consisting of $\mathrm{CMV}$ infected and mock infected human fibroblasts were tested. Moreover, as control probes, the CMV unlabelled DNA probe and the digoxigenin labelled pACYC 184 DNA probe were used. Herpes simplex virus types I and II biotinylated probes (Enzo Biochem, New York) visualised by avidin biotin horseradish peroxidase, was also used as a negative control in CMV positive samples.

Cerebrospinal fluid cells were treated by indirect immunofluorescence using a pool of anti-CMV monoclonal antibodies (anti-p65 from Clonab; anti-early antigens and anti-late antigens from Du Pont), diluted 1 in 20 in PBS, and visualised with fluorescein conjugated $\mathrm{Fab}$ fragments of rabbit immunoglobulin to mouse immunoglobulin (Dako), diluted 1 in 40 in PBS.

The CMV antigenaemia assay was performed in PMNLs, collected and fixed as 
described before, ${ }^{14}$ by indirect immunofluorescence using the pool of monoclonal antibodies and the fluorescein conjugated Fab fragments described above.

\section{Results}

Of the 10 patients with AIDS examined, positive findings for the detection of CMV DNA in cerebrospinal fluid cells by in situ hybridisation were found in six patients. Cerebrospinal fluid cells, positive for CMV DNA, stained dark blue showing a strong positive signal with a good preservation of cellular morphology and absence of background staining (fig $1)$. The percentage of CMV positive cells ranged from $6 \%$ to $30 \%$ of the cells. The in situ hybridisation assay using our CMV DNA probe on cerebrospinal fluid cells was shown to be specific on the basis of the results of the following control reactions: (a) no signal was observed in CMV positive samples when the primary incubation with anti-digoxigenin Fab fragments was either omitted or replaced with an incubation with non-immune sheep serum; (b) CMV positive cells did not stain at all after hybridisation with the unlabelled probe and with the digoxigenin labelled pACYC 184 DNA probe; (c) CMV positive cerebrospinal fluid cells appeared without a positive signal when they were hybridised with the biotinylated DNA probe for the detection of herpes simplex virus types I and II. Moreover, the cerebrospinal fluid samples from patients with AIDS in which cryptococcal, mycobacterial, or toxoplasma encephalitis were diagnosed proved negative for the presence of CMV DNA.

To assess the reproducibility of our results, all the samples were retested twice and the results agreed with previous findings.

Out of the six patients who proved positive for the presence of CMV DNA in cerebrospinal fluid cells, in five we were also able to analyse cerebrospinal fluid cells for the presence of CMV induced antigens and all these five proved positive (fig 2 ). In one patient cerebrospinal fluid cell specimens were no longer available. The six patients also proved positive for CMV DNA in blood PMNLs by in situ hybridisation (fig 3) and for antigenaemia. In the six patients positive for CMV in cerebrospinal fluid cells the cranial computed tomogram showed in two a focal parenchymal lesions with contrast uptake, in one a cortical atrophy with diffuse enlargement of ventricles, and in three a mild athrophy. Moreover, in four out of the six positive patients, other CMV diseases were detected: CMV retinitis with white exudate with associated haemorrhage ( $=1)$; interstitial CMV pneumonitis $(n=1)$; and CMV retinitis together with CMV pneumonitis $(n=2)$. Out of these six patients positive for $\mathrm{CMV}$ in cerebrospinal fluid cells, five were treated with ganciclovir (DHPG) $(10 \mathrm{mg} / \mathrm{kg}$ daily) while one was not treated because of renal failure and pancytopenia. Of the five treated with ganciclovir, one patient died during treatment and in this case histological examination of the brain at necropsy showed microglial nodules with numerous inclusion bearing cells; four showed a clinical improvement after one month of treatment. Clinical improvement was assessed by the disappearance of focal parenchymal lesions in the brain at computed tomography in two patients, by improved vision in one patient with retinitis, stabilised retinitis in another one, and in the resolution
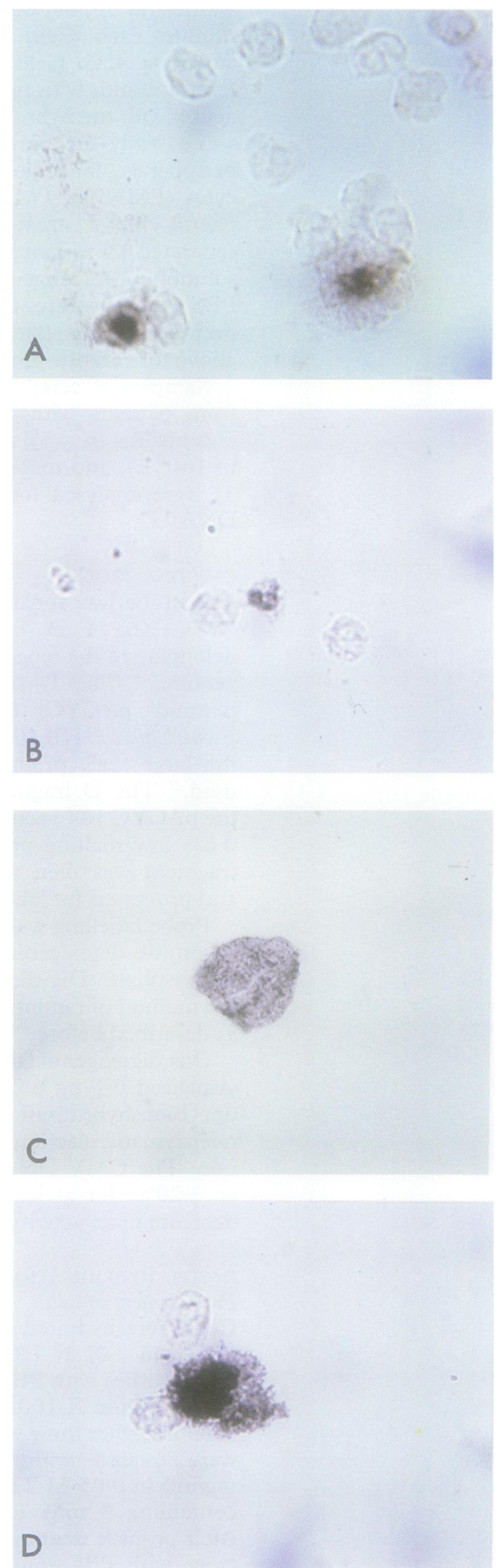

Figure 1 CMV DNA positive cells in cerebrospinal fluid specimens: 
Figure 2 CMV induced antigens, positive cells in cerebrospinal fluid specimens.
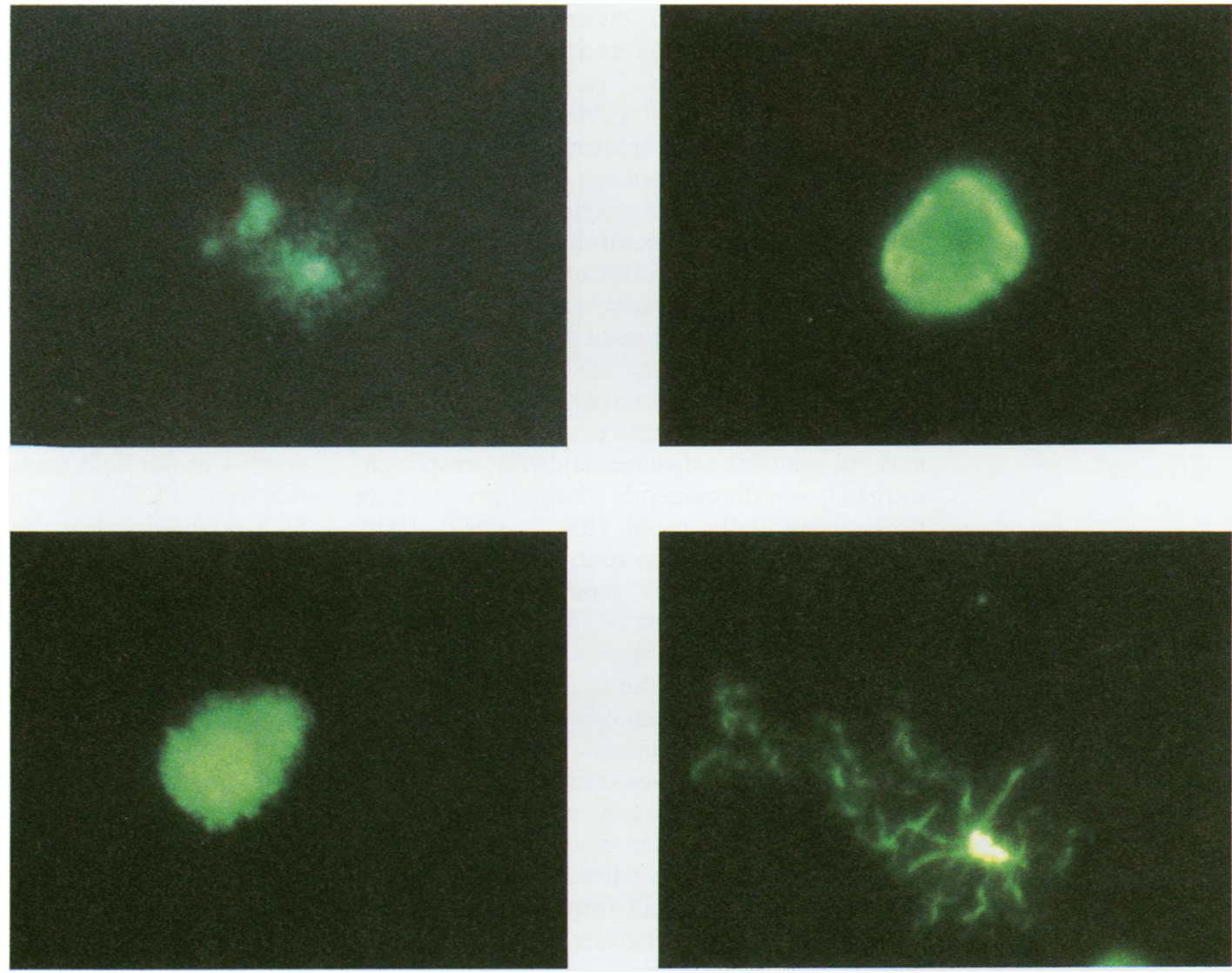

of interstitial pneumonitis at radiological examination in two patients. Clinical findings of the six patients positive for CMV DNA in cerebrospinal fluid cells are summarised in the table.

Of the four patients negative for CMV DNA in cerebrospinal fluid cells, all four proved negative for viral antigens in the same cells. Of these four patients, three proved negative for CMV DNA and CMV antigens in blood PMNLs while one proved positive for both CMV DNA and CMV antigenaemia.

Of the four patients negative for CMV DNA in cerebrospinal fluid cells, one proved positive for varicella zoster virus in cell cultures infected with cerebrospinal fluid, in one, AIDS dementia complex, and in two, a progressive multifocal leucoencephalopathy was diagnosed on the basis of clinical course and magnetic resonance imaging.

Discussion

This study explored the use of an in situ hybridisation assay technique using digoxigenin labelled CMV DNA probes, to detect

Figure 3 CMV DNA positive cell in blood sample.

Results of laboratory and clinical findings in six patients positive for CMV DNA in cerebrospinal fluid cells

\begin{tabular}{|c|c|c|c|c|c|c|}
\hline $\begin{array}{l}\text { Case } \\
\text { No }\end{array}$ & $\begin{array}{l}\text { Presence } \\
\text { of CMV } \\
\text { DNA in } \\
\text { cerebrospinal } \\
\text { fluid cells }\end{array}$ & $\begin{array}{l}C M V \\
D N A \text { in } \\
P M N \text { cells }\end{array}$ & Brain scan & $\begin{array}{l}\text { Other } C M V \\
\text { manifestations }\end{array}$ & $\begin{array}{l}\text { CMV } \\
\text { treatment }\end{array}$ & $\begin{array}{l}\text { Clinical } \\
\text { outcome } \\
\text { after one } \\
\text { month of } \\
\text { treatment }\end{array}$ \\
\hline 1 & + & + & Mild athrophy & & & No change \\
\hline 2 & + & + & Mild athrophy & Pneumonitis, retinitis & DHPG & Death \\
\hline 3 & + & + & Focal parenchymal lesions & Pneumonitis, retinitis & DHPG & Improvement \\
\hline 4 & + & + & Focal parenchymal lesions & & DHPG & Improvement \\
\hline 5 & + & + & Mild athrophy & Retinitis & DHPG & Improvement \\
\hline 6 & + & + & Severe athrophy & Pneumonitis & DHPG & Improvement \\
\hline
\end{tabular}


CMV DNA in the cerebrospinal fluid cells of patients with AIDS and suspected viral encephalitis.

Early diagnosis of CMV encephalitis is essential for effective treatment with antiviral agents, to curb progression of the disease. A rapid and specific detection procedure is therefore essential. Radiological and computed tomography studies of the brain during CMV infection frequently lack positive or specific findings. Detection of CMV in cerebrospinal fluid by culture or demonstration of intrathecal specific antibody can be used, but results are often negative especially during the early phase of the disease. Hybridisation techniques using digoxigenin labelled probes have proved useful for rapid viral diagnosis, with the advantage of a sensitivity similar to radiolabelled probes, short processing time, and stability of the probes..$^{201}$ Moreover, in situ hybridisation offers the advantage of specifically and sensitively identifying viral genomic sequences within infected cells with an excellent topological resolution..$^{122}$

To avoid problems caused by bacterial contamination of specimens, which could give false positive reactions in the CMV DNA hybridisation assay, we used as a viral probe only the CMV XbaI D fragment, which was excised and separated from the pACYC 184 vector; this avoided cross-reactions between the vector DNA and the plasmid DNAs present in contaminating bacteria.

After hybridisation with target DNA, the digoxigenin labelled probes were visualised with anti-digoxigenin $\mathrm{Fab}$ fragments conjugated with alkaline phosphatase. The use of Fab fragments avoids non-specific interactions that might arise with cells expressing $\mathrm{Fc}_{\mathrm{c}}$ receptors. Moreover, having alkaline phosphatase as an enzyme marker overcomes the disadvantage of horseradish peroxidase, such as the presence of endogenous enzyme in the test specimens. ${ }^{23} 24$

The entire assay could be performed in about eight hours, as the hybridisation time was shortened to three hours without loss of sensitivity.

Central nervous system disease with CMV has been reported in both immunocompetent and immunodepressed subjects. ${ }^{255-27} \mathrm{Al}-$ though CMV encephalitis is rare in adult immunocompetent subjects or immunocompromised transplant recipients, it occurs more frequently in patients with AIDS. In our study six such patients out of 10 suspected of having viral encephalitis proved positive for the detection of CMV DNA in cerebrospinal fluid cells. The results obtained on the presence of CMV DNA in cerebrospinal fluid cells were consistent with the presence of CMV antigens in the same cells. Ganciclovir treatment of five of the six CMV positive patients resulted in a clinical remission of four, thus strengthening the diagnosis of CMV encephalitis, while one died during the period of treatment. In this patient, evidence of CMV infection of the brain was found at necropsy.

In our study all six patients positive for CMV DNA in cerebrospinal fluid cells, also proved positive for CMV DNA in PMNLs, which are known to be the major carrier of virus in the blood..$^{28} \mathrm{~A}$ recent study on the correlation between viraemia and glial nodule encephalitis after systemic CMV infection in a guinea pig model has shown that infection of the brain may follow direct vascular infection. ${ }^{29}$ In patients with AIDS prolonged viraemias associated with the compromised capacity of the host to clear the virus may facilitate the spread of CMV infection to the brain, often resulting in symptomatic encephalitis. Recently, some authors have described rapid detection of CMV DNA in cerebrospinal fluid using the polymerase chain reaction (PCR) ${ }^{30-32}$; this method offers very high sensitivity, but the extreme sensitivity of PCR could give false positive results if cerebrospinal fluid specimens, obtained by lumbar puncture, are even minimally contaminated with patients' blood in which CMV DNA may be present without involvement of central nervous system. As PCR is now being widely used it would be interesting to compare the results of PCR with those of in situ hybridisation on cerebrospinal fluid samples from patients with AIDS and a clinical diagnosis of viral encephalitis.

In conclusion, our findings show that in situ hybridisation assay in cerebrospinal fluid cells can be a useful tool for a rapid diagnosis of CMV encephalitis, prompting specific antiviral treatment. The skilful technical help of Ms Marinella Plazzi is gratefully
acknowledged.
This work was partially supported by "CNR Target Project
Biotechnology and Bioinstrumentation" and by the Italian Biotechnology and Bioinstrumentation
Ministry of Health, AIDS Project 1994.

1 Drew WL. Cytomegalovirus infection in patients with AIDS. F Clin Infect Dis 1992;14:608-15.

2 Rubin RH. Infection in the renal transplant recipient. In: Brenner BM, Stein JH, Milford EL, eds. Renal transplantation. New York: Churchill Livingstone, 1989:147-80.

3 Petito CK, Cho ES, Lemann W, Navia BA, Price RW. Neuropathology of acquired immunodeficiency syndrome (AIDS): an autopsy review. $\mathcal{f}$ Neuropathol Exp Neurol 1986;45:635-46.

4 Snider WD, Simpson DM, Nielsen S, Gold JWM, Metroka CE, Posner JB. Neurological complication of acquired immune deficiency syndrome: Analysis of 50 patients. Ann Neurol 1983;14:403-18.

5 Donovan Post MJ, Hensley GT, Moskowitz LB, Fischl M. Cytomegalic inclusion virus encephalitis in patients with AIDS: CT, clinical and pathological correlations $A m \mathcal{F}$ Neuroradiol 1986;7:275-80.

6 Morgello S, Cho ES, Nielsen S, Devinsky O, Petito CK Cytomegalovirus encephalitis in patients with acquired immunodeficiency syndrome. An autopsy study of 30 cases and a review of the literature. Hum Pathol 1987; 18:289-97.

7 Vinters HV, Kwok MK, Ho MW, Anders KH, Tomiyasu $\mathrm{U}$, Wolfson WL, et al. Cytomegalovirus in the nervous system of patients with acquired immune deficiency synsystem of patients with acquired immune
drome (AIDS). Brain 1989;112:245-68.

8 Mcintosh K. Diagnostic virology. In: Fields BN, Knipe DM, eds. Virology. 2nd edn. New York: Raven Press, 1990:423-4.

9 Musiani M, Zerbini M, Gentilomi G, Gallinella G, Venturoli S, Gibellini D, et al. Rapid detection of cytomegalovirus DNA in urine samples with a dot blot hybridization immunoenzymatic assay. $f$ Clin Microbiol 1990;28:2101-3.

10 Musiani M, Zerbini M, Gentilomi G, Gibellini D, Gallinella G, Venturoli S, et al. Detection of CMV DNA in clinical samples of AIDS patients by chemiluminescence hybridization. $\mathcal{F}$ Virol Methods 1992;38:1-10.

11 Gentilomi G, Musiani M, Zerbini M, Gallinella G, Gibellini D, La Placa M. A hybrido-immunocytochemica assay for the in situ detection of cytomegalovirus DNA using digoxigenin-

12 Musiani M, Gentilomi G, Zerbini M, Gibellini D, 
Gallinella G, Pileri $S$, et al. In situ detection of cytomegalovirus DNA in biopsies of AIDS patients using a hybrido-immunocytochemical assay. Histochemistry 1990;94:21-5.

13 Wiley CA, Schrier RD, Denaro FJ, Nelson JA, Lampert $\mathrm{PW}$, Oldstone MBA. Localization within the CNS of cytomegalovirus proteins and genome during fulminant infection in an AIDS patient. 7 Neuropathol Exp Neurol 1986;45:127-9.

14 Revello MG, Percivalle E, Zavattoni M, Parea M, Grossi P, Gerna G. Detection of human cytomegalovirus immediate early antigen in leukocytes as a marker of viremia in immunocompromised patients. F Med Virol

15 La Femina RL, Hayward GS. Structural organization of the DNA molecules from human cytomegalovirus. In: Fields BN, Jaenisch R, eds. Animal virus genetics. New York: Academic Press, 1980:39-55

16 Thomsen DR, Stinski MF. Cloning of the human cytomegalovirus genome as Xba I endonuclease fragments. Gene 1981;16:207-16.

17 Sambrook J, Fritsch EF, Maniatis T. Molecular cloning: a laboratory manual. Cold Spring Harbor, New York: Cold Spring Harbor Laboratory, 1989.

18 Feinberg AP, Vogelstein B. A technique for radiolabeling DNA restriction endonuclease fragments to high specific activity. Analyt Biochem 1983;132:6-13.

19 Musiani M, Zerbini M, Gibellini D, Gentilomi G, La Placa M, Ferri E, et al. Chemiluminescent assay for the detection of viral and plasmid DNA using digoxigeninlabelled probes. Analyt Biochem 1991;194:394-8.

20 Azzi A, Zakrewska K, Gentilomi G, Musiani M, Zerbini $M$. Detection of $B 19$ parvovirus infections by a dot -blot hybridization assay using a digoxigenin-labelled probe. f Virol Methods 1990;27:125-34.

21 Kimpton CP, Corbitt G, Morris DJ. Detection of cytomegalovirus DNA using probes labelled with digoxicytomegalovirus DNA using probes labell

22 Gentilomi G, Musiani M, Zerbini M, Gibellini D,
Gallinella G, Venturoli S. Double in situ hybridization for detection of herpes simplex virus and cytomegalovirus DNA using non radioactive probes. f Histochem Cytochem 1992;40:421-5.

23 Streefkerk JG. Inhibition of erythrocyte pseudoperoxidase activity by treatment with hydrogen peroxide following methanol. F Histochem Cytochem 1972;20:829-34.

24 Weir EE, Pretlow TG, Pitts A, William EE. Destruction of endogenous peroxidase activity in order to locate cellular antigens by peroxidase labeled antibody. $\mathcal{f}$ Histochem Cytochem 1974;22:51-6.

25 Dorfman LJ. Cytomegalovirus encephalitis in adults. Neurology 1973;23:136-44.

26 Nielsen SL, Petito CK, Urmacher CD, Posner JB. Subacute encephalitis in acquired immune deficiency syndrome: a postmortem study. Am f Clin Pathol 1984; 82:678-82.

27 Sissons JGP. Human cytomegalovirus infection. Thorax 1989;44:241-6.

28 Dankner WE, McCutchan JA, Richman DD, Hirata K, Spector SA Localization of human cytomegalovirus in peripheral blood leukocytes by in situ hybridization. F Infect Dis 1990;161:31-6.

29 Booss J, Winkler SR, Griffith BF, Kim JH. Viremia and glial nodule encephalitis after experimental systemic glial nodule encephalitis after experimental systemic

30 Wolf DG, Spector SA. Diagnosis of human cytomegalovirus central nervous system disease in AIDS patients by DNA amplification from cerebrospinal fluid. F Infect Dis 1992;166:1412-5.

31 Gozlan J, Salord JM, Roullet E, Baudrimont M, Caburet $\mathrm{F}$, Picard $\mathrm{O}$, et al. Rapid detection of cytomegalovirus DNA in cerebrospinal fluid of AIDS patients with neurological disorders. F Infect Dis 1992;166:1416-21.

32 Cinque $P$, Vago L, Brytting M, Castagna A, Accordini A, Sundqvist VA, et al. Cytomegalovirus infection of the central nervous system in patients with AIDS: diagnosis by DNA amplification from cerebrospinal fluid. $\mathcal{F}$ Infect Dis 1992;166:1408-11. 